\title{
Folding Analysis for Thin-walled Deployable Composite Boom
}

\section{Jiang-Bo Bai $^{{ }^{*}}$, Di Chen ${ }^{1}$, Jun-Jiang Xiong ${ }^{{ }^{*}}$, R Ajit Shenoi $^{2}$}

1 School of Transportation Science and Engineering, Beihang University, Beijing, 100191, People's Republic of China (*, corresponding author: baijiangbo@buaa.edu.cn, jjxiong@buaa.edu.cn) 2 Southampton Marine and Maritime Institute, University of Southampton, Southampton, UK Abstract: Thin-walled deployable composite structures with high strain ability are of
considerable interest and increasingly used in aerospace field due to their superior
mechanical behaviour and folding function. This paper seeks to investigate large folding
deformation behaviour of a thin-walled deployable composite boom (DCB) made of high
strain carbon-fibre-reinforced-plastics fabricated by vacuum-bag and co-bonding
technologies. Large deformation function tests are conducted to determine tensile,
compression and folding behaviours of the DCB. Geometrically nonlinear, explicit and
standard, finite element models and an analytical model are implemented to characterize
the tensile and compression behaviours of the DCB, and the deviations of predictions from
experiments are in an acceptable scatter. Furthermore, a geometrically nonlinear and
explicit finite element model is also generated for folding analysis of the DCB, and a good
correlation between predictions and experiments has been achieved. Key words: folding; deployable; large deformation; composite boom; geometrically nonlinear

\section{NOMENCLATURE}

$C_{0} \quad$ transformation variable

$E_{\theta} \quad$ off-axis elastic modulus of a ply in tangential direction of $\theta$

$M_{x} \quad$ resultant moment on longitudinal section

$P_{c} \quad$ flattening force in compression model of the DCB

$P_{t} \quad$ tensile force in tensile model of the DCB

$r \quad$ curvature radius of neutral axis on cross section of flattening DCB

$r_{0} \quad$ initial curvature radius of neutral axis on cross-section of the DCB 
$\delta_{y} \quad$ deflection at the point $\mathrm{C}$ in horizontal direction owe to the tensile deformation

$\delta_{z} \quad$ deflection at the apex A in vertical direction owe to the compression deformation

$\varphi \quad$ central angle of neutral axis on cross section of the flattening DCB

$\varphi_{0} \quad$ initial central angle of neutral axis on cross section of the DCB

CFRP carbon-fibre-reinforced-plastics

DCB deployable composite boom

FE Finite element

FEA Finite element analysis

\section{INTRODUCTION}

Limitation of storage capacity in launch vehicles drives the growing usage of deployable structures for large space structures such as solar sails and reflector antennas etc. These structures can be packaged into a small volume before launch and unfolded into large configurations during their working state in space ${ }^{[1-5]}$. Due to the superior stiffness and strength as well as ultralight weight characteristics, thin-walled deployable composite structures made of high strain composites are a potential solution for launching large constructions for space missions ${ }^{[6-8]}$.

As a typical deployable structure, thin-walled composite tape hinges are commonly used for the folding element of deployable configurations, and a large body of research exists to characterize deployment mechanism and folding behaviour for tape hinges ${ }^{[9]}$. Soykasap ${ }^{[10,11]}$ presented a deployable composite antenna reflector demonstrator with tape hinges. The folding behaviour for tape spring hinges under two- and three-dimensional folds was predicted using analytical and finite element (FE) methods, and the predictions of moment-rotation curves correlated well with the experiments. Finally, the folded configuration and regions with high strain level were identified using a geometrically nonlinear FE model. Seffen et al. ${ }^{[12]}$ examined the moment-rotation relationships of curved tape hinges in folding deformation through experimental, analytical and numerical methods. It was found that, for curved tape hinges and straight tape hinges, there was an important difference in equal-sense folds with small rotation angles. Dewalque et al. ${ }^{[13,14]}$ investigated geometrically nonlinear behaviour of tape springs from experimental and numerical methods. The buckling, formation of fold and hysteresis were characterized, and the effect of 
structural dissipation on the dynamic simulation for the tape spring was examined.

Thin-walled deployable composite booms (DCBs) are self-deployed structures in the length direction which are applicable for producing the main supporting parts of deployable configurations including solar sail, gravity-gradient boom etc. A significant amount of research has been conducted to analyze deployment mechanism and folding behavior of the DCB. Sickinger et al. ${ }^{[15]}$ numerically and experimentally investigated axial compression and bending as well as vibration behaviours, temperature pattern and thermal deformation, and coating effect of a lenticular DCB. It was found

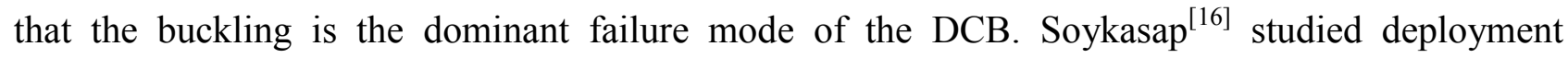
mechanism and folding behaviour of the DCB with an integral folding hinge by using experimental and nonlinear FE methods. The folding hinge consisting of three tape springs makes the folding deformation process of the DCB much easier. However, the hinge significantly decreases the flexure stiffness of the DCB. Bai et al. ${ }^{[17-20]}$ proposed an analytical model to evaluate the folding behaviour of a lenticular DCB in extreme folding deformation, and the predicted results agreed well with the experiments. Moreover, the temperature distribution and thermal buckling properties of lenticular DCB were determined and analyzed numerically and experimentally. Laurenzi et al. ${ }^{[21,22]}$ numerically simulated nonlinear buckling and folding behavior of a C-sectional DCB. Geometrical parameters were systematically analyzed and evaluated to reduce the stress level of the DCB in folding process. Fernandez et al. ${ }^{[23,24]}$ examined folding and deploying behaviours, structural deploying stiffness, shape and ply effect, fabrication methods for a series of different types of DCBs for the possible missions of solar sails, gossamer sail system, etc.

From the previous reviews, it is obvious that deployment mechanism and folding behavior of thin-walled deployable composite structures (e.g., composite tape hinges and DCBs, etc.) have received comprehensive investigation over the last several decade years. However, the deployment and folding mechanisms of lenticular DCB are extremely complex, and there always exist three-dimensional folding, complex contacts (e.g., self-contact and general contact between the DCB and folding devices, etc.), complicate boundary conditions, etc. Therefore, the folding behavior of lenticular DCB are scarcely reported and the related mechanism is not systematically studied $^{[17,18]}$. In reality, due to excellent folding behaviour and good flexure stiffness resulted from its closed thin-walled cavity construction, lenticular DCBs have received much interest in engineering design of thin-walled deployable composite structures. Hence, it is important and crucial to fully understand the folding behaviour of lenticular DCB and it is desirable to have a 
technique to evaluate the folding behaviour.

This paper attempts to develop a technique to characterize and assess the folding behaviour of lenticular DCB for engineering design of thin-walled deployable composite structures. The underpinning work comprises three features: (1) large deformation function tests are conducted to determine tensile, compression and folding behaviours of the DCB; (2) geometrically nonlinear, explicit and standard, finite element models and an analytical model are generated to characterize the tensile and compression behaviours of the $\mathrm{DCB}$, and the predictions are compared with the experiments; (3) a geometrically nonlinear and explicit finite element model is also generated for folding analysis of the $\mathrm{DCB}$, and the simulations are verified by the experiments.

\section{LARGE DEFORMATION EXPERIMENTS}

\subsection{Material and Specimens}

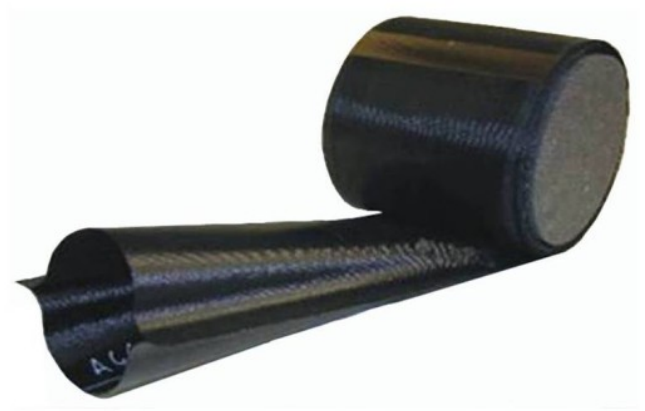

Figure 1 Thin-walled lenticular $\mathrm{DCB}^{[8]}$

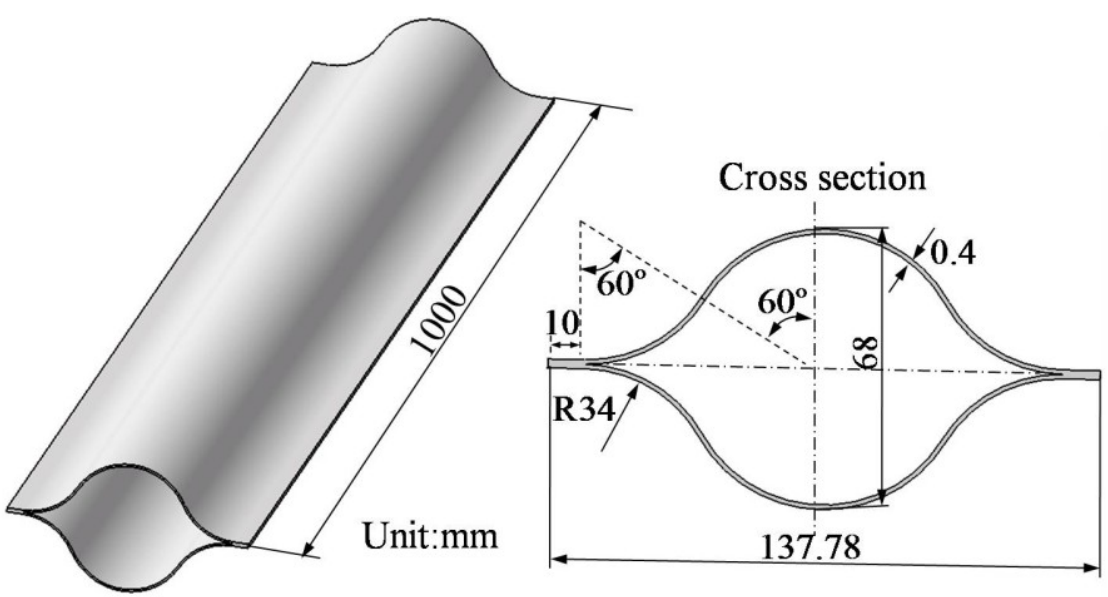

Figure 2 Geometry and dimensions of lenticular DCB

In a practical application, the thin-walled DCB made of high strain composites can be elastically folded and then recovered to its original state using the stored strain energy (shown in Figure 1). Whole folding process is usually decomposed into the tensile or compressive deformation to a flattening state and then the coiling deformation, and thus it is important to investigate tensile, 
compressive and folding deformation behaviours of the DCB. Two types of thin-walled DCB specimens were prepared, and all specimens had the same cross-section, which were constructed by two identical curved thin-walled composite shells. The geometry and dimensions of specimen are illustrated in Figure 2. The length of specimen for tensile and compressive tests is $65 \mathrm{~mm}$ and that for folding tests is $1000 \mathrm{~mm}$. The thickness of thin-walled composite shells with the same ply orientation of [45/-45/0/-45/45] is $0.4 \mathrm{~mm}$. The DCB specimens were produced by T300/5228A prepreg material, where two identical thin-walled composite shells were firstly cured by vacuum-bag method and then bonded together (shown in Figure 3).

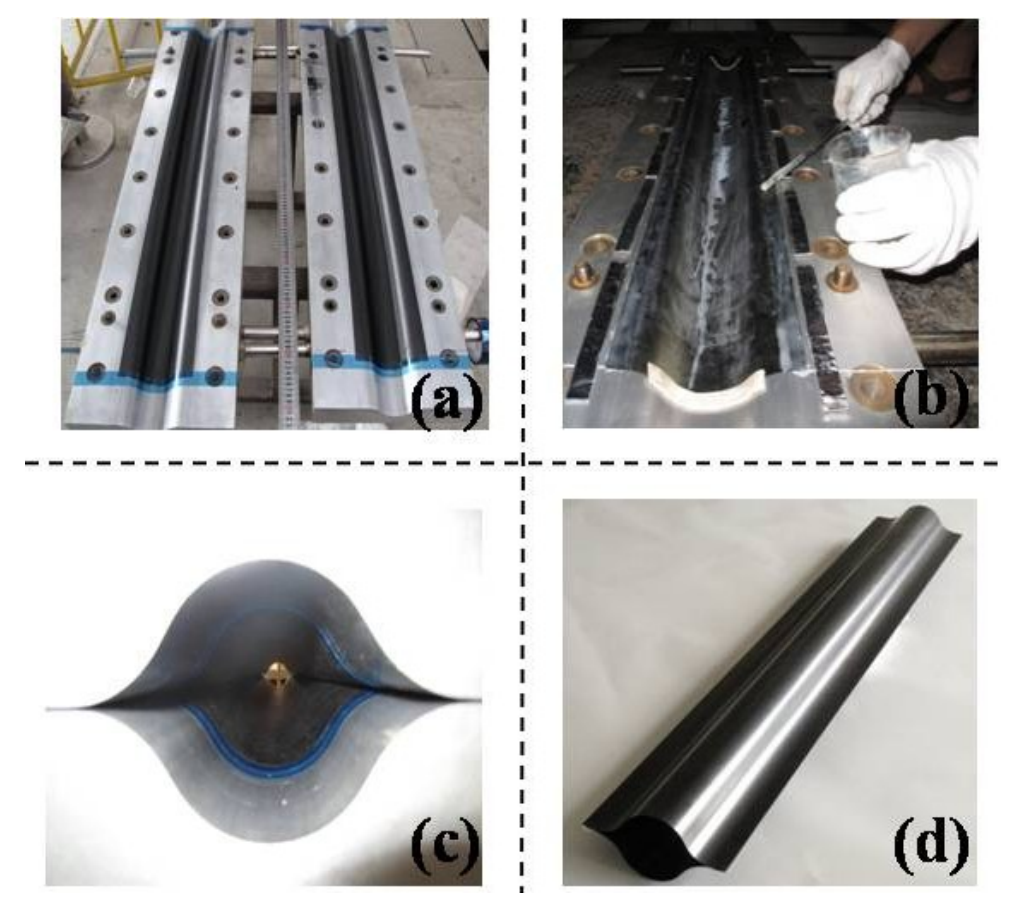

Figure 3 Preparation process for the DCB specimen: (a) semi-DCB shells in the mould (b) bonding (c) curing adhesive (d) DCB specimen

\subsection{Tensile and Compression Tests}

All tensile and compressive tests for the DCB specimens were conducted on an INSTRON servo-hydraulic machine at room temperature. The loading rate was at $2 \mathrm{~mm} / \mathrm{min}$, which made the tensile and compressive tests as quasi-static loading processes. Loading and boundary conditions in tensile tests are shown in Figure 4. The DCB specimen was gradually stretched into a flattening state with an increase in the tensile loading (shown in Figure 4), and then the tensile specimen could recover its original shape after unloading. Whole tensile deformation process of specimen was elastic without any damage. Figure 5 shows tensile force versus displacement curves of the DCB in extensional process. From Figure 5, it is clear that the tensile force versus displacement curves are 
nonlinear, but approximate linear response within a tensile deformation range of less than $15 \mathrm{~mm}$. Loading and boundary conditions in compressive tests are shown in Figure 6. Like the tensile tests, the DCB specimen was gradually compressed into a flattening state with an increase in the compressive loading (shown in Figure 6), and then the compressive specimen could recover its original shape after unloading. Figure 7 shows compression force versus displacement curves of the DCB in compression deformation. From Figure 7, it can be shown that the compression force versus displacement curves are also nonlinear, but approximately linear within a compressive deformation range of less than $60 \mathrm{~mm}$.
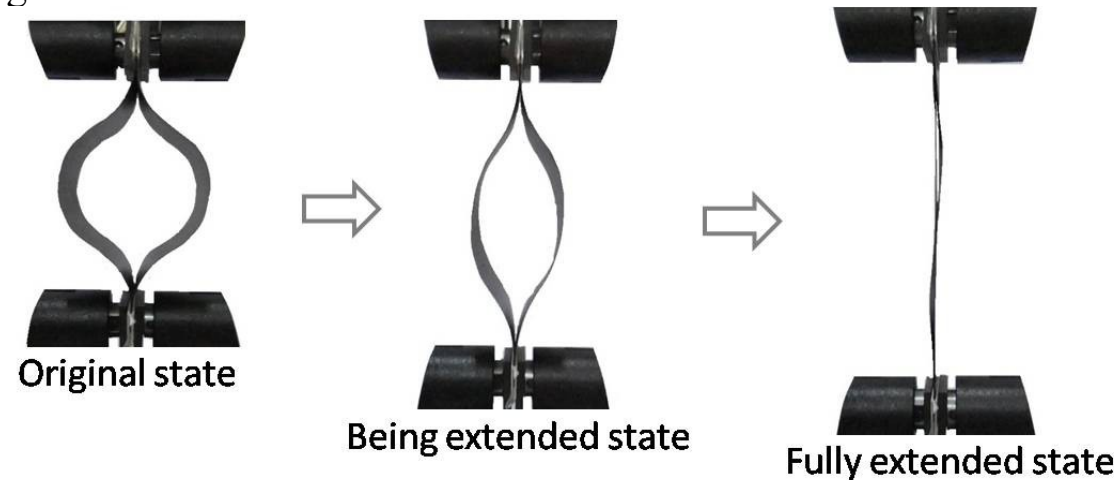

(a) Experiments
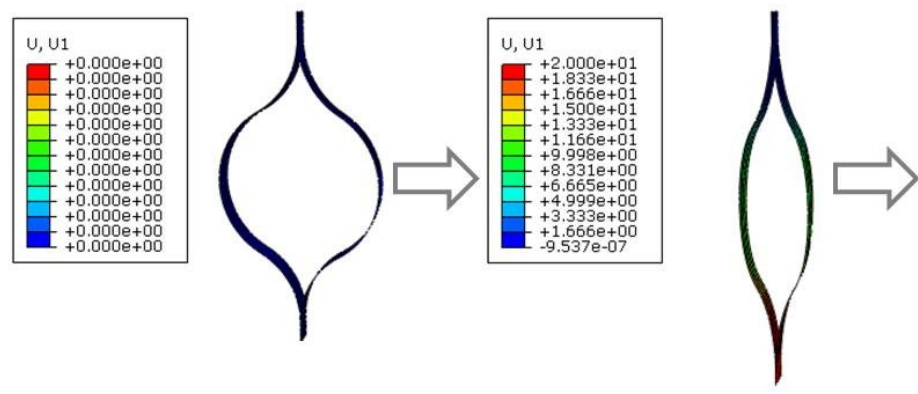

Original state

Being extended state

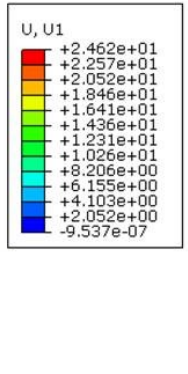

(b) Simulations

Figure 4 Tensile deformation of the DCB 


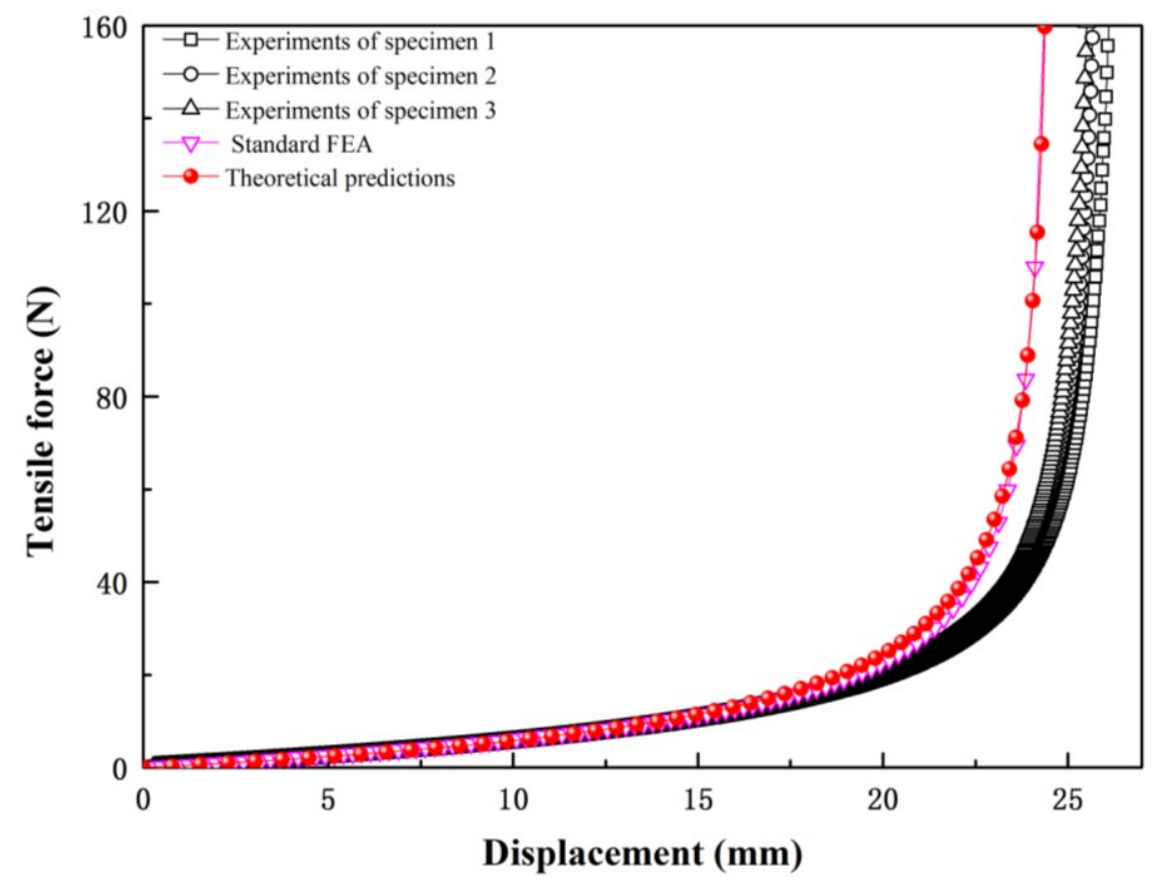

(a) Experiments and predictions using standard FEA and theory

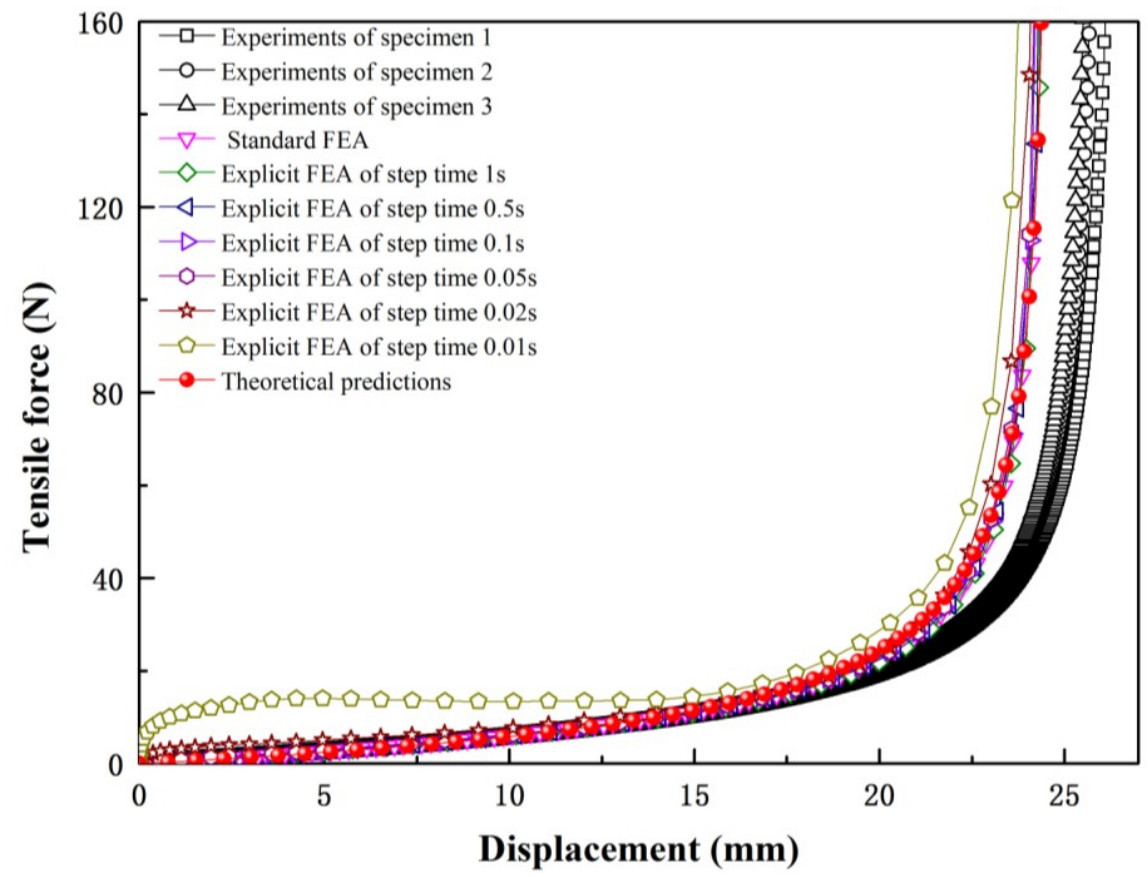

(b) Experiments and predictions using explicit FEA and theory

Figure 5 Tensile force versus displacement curves of the DCB in extending process 


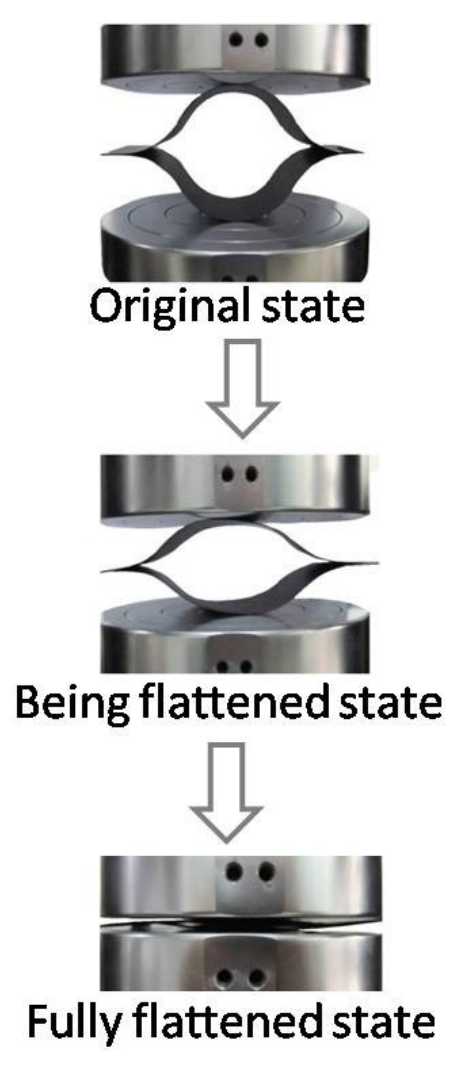

(a) Experiments

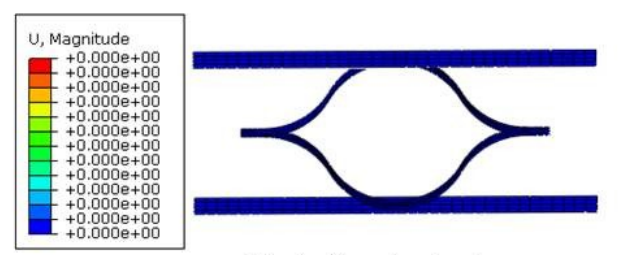

Original state
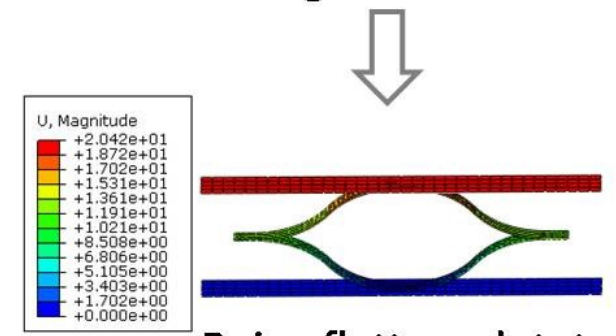

Being flattened state
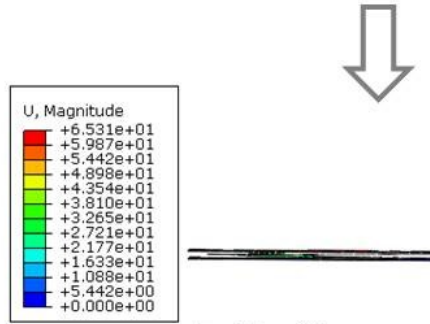

Fully flattened state

(b) Simulations

Figure 6 Compression deformation of the DCB

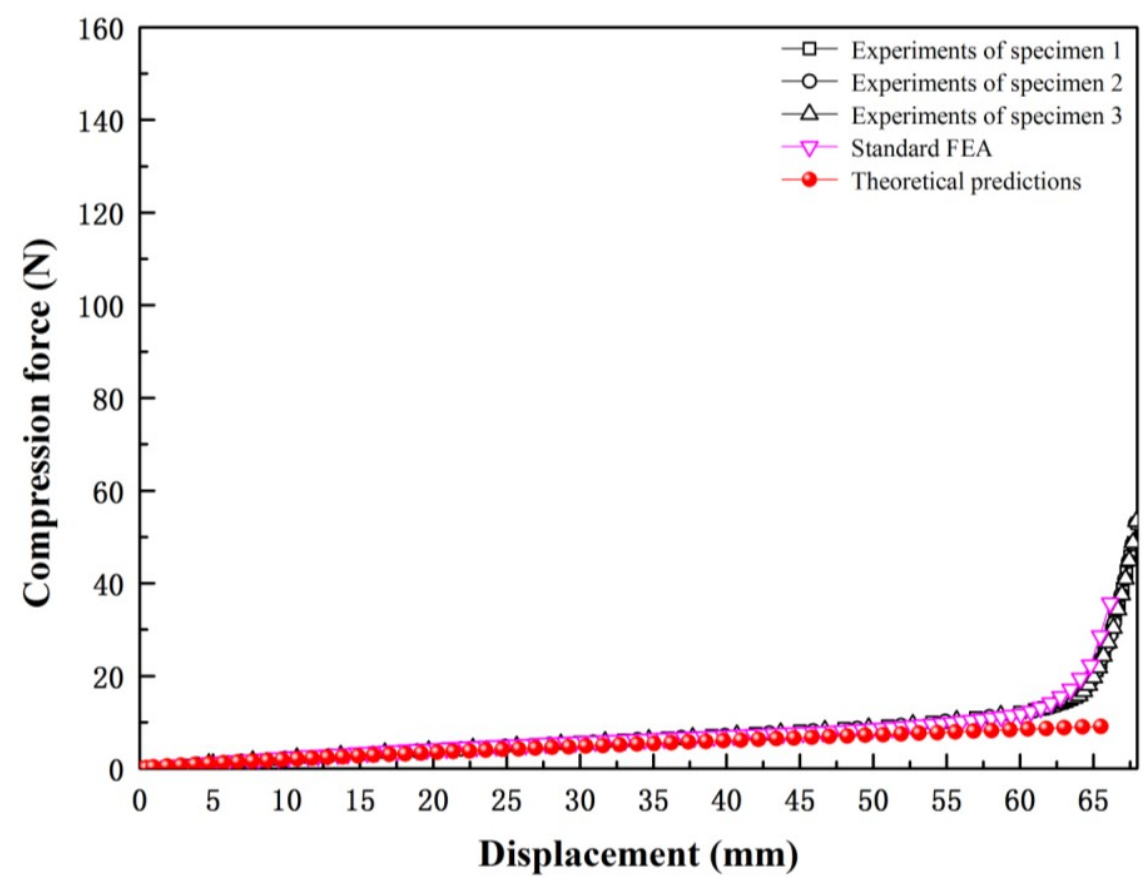

(a) Experiments and predictions using standard FEA and theory 


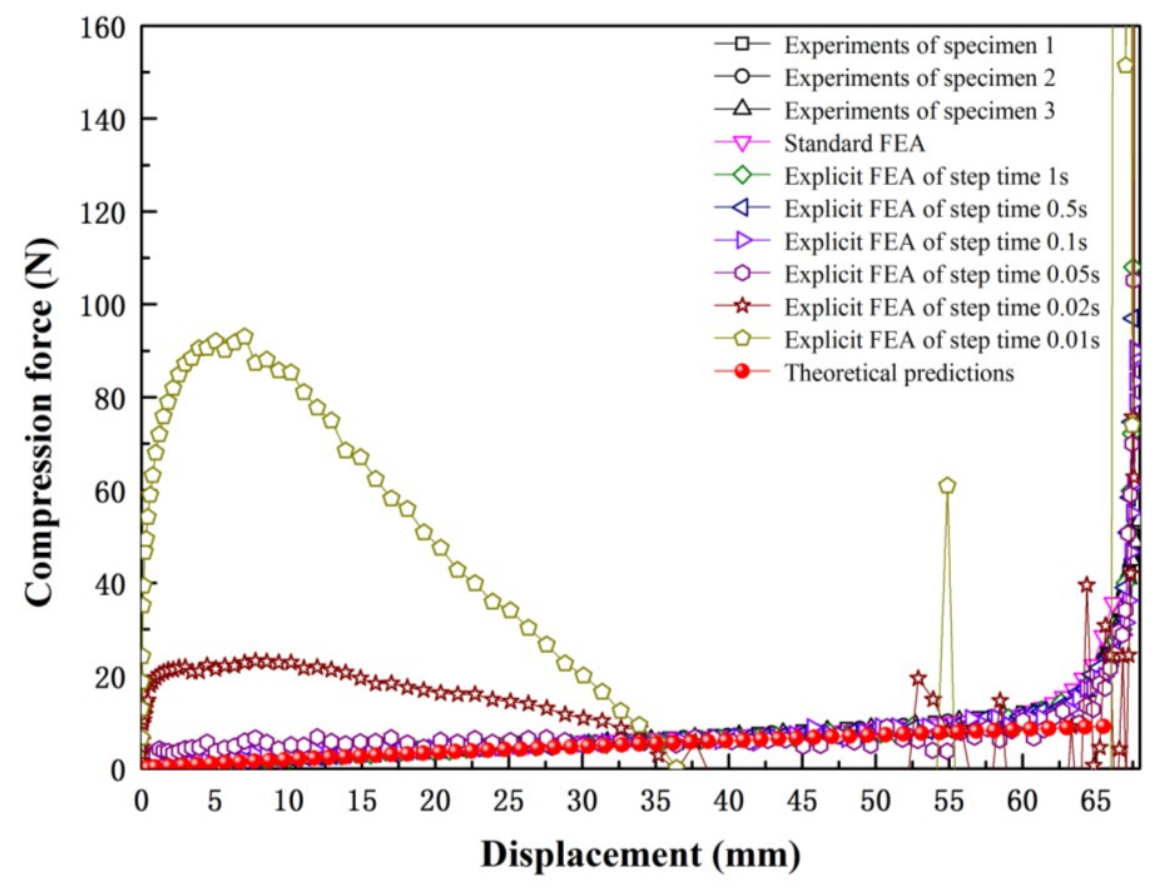

(b) Experiments and predictions using FEA and theory

Figure 7 Compression force versus displacement curves of the DCB in flattening process

\subsection{Folding Tests}

A coiling mechanics machine was designed and manufactured to conduct the folding tests of the DCB (shown in Figure 8). The machine can drive and record the coiling deformation of the DCB, in which the main parts include a central driving roller with a radius of $80 \mathrm{~mm}, 11$ constraint shafts, torque sensors and frame structure, and all gap distances between the central driving roller and the constraint shafts are $8 \mathrm{~mm}$. The folding tests were carried out at a uniform rotational displacement rate in a dry state at room temperature. The coiling deformation process of the DCB specimen is shown in Figure 8. One end of the DCB specimen was pressed into a flattening state and fixed on the central driving roller, which was followed by the beginning of coiling deformation (shown in Figure 8). The DCB specimen was smoothly flattened and coiled by the machine without any damage, and the coiled specimen was able to recover its original shape after unloading. Figure 9 shows a driving rotational moment versus rotational displacement curve for the folding deformation. It is obvious from Figure 9 that the driving rotational moment increases with an increase in the rotational displacement within the initial small deformation range and then reaches a stable level of about $1 \mathrm{~N} \cdot \mathrm{m}$. This implies that the folding deformation is proceeded stably. 


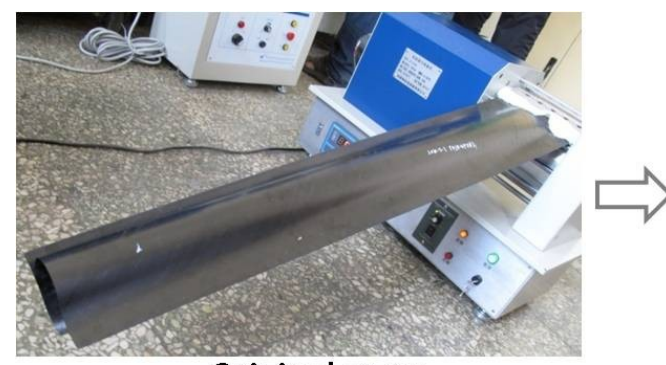

Original state

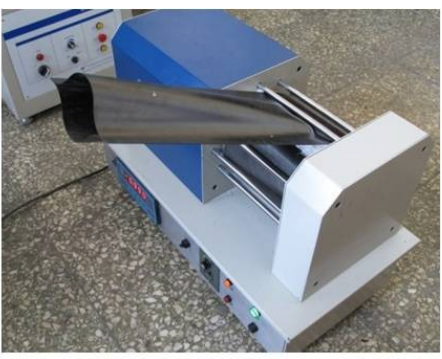

Being coiled state

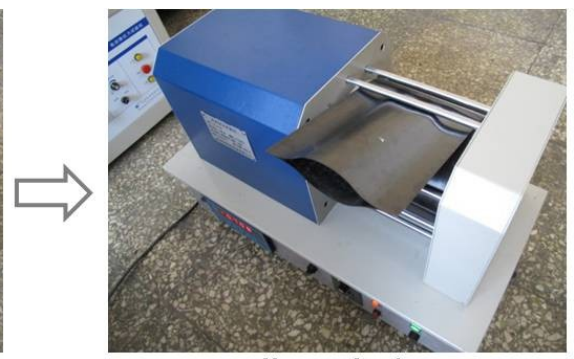

Fully coiled state

(a) Experiments
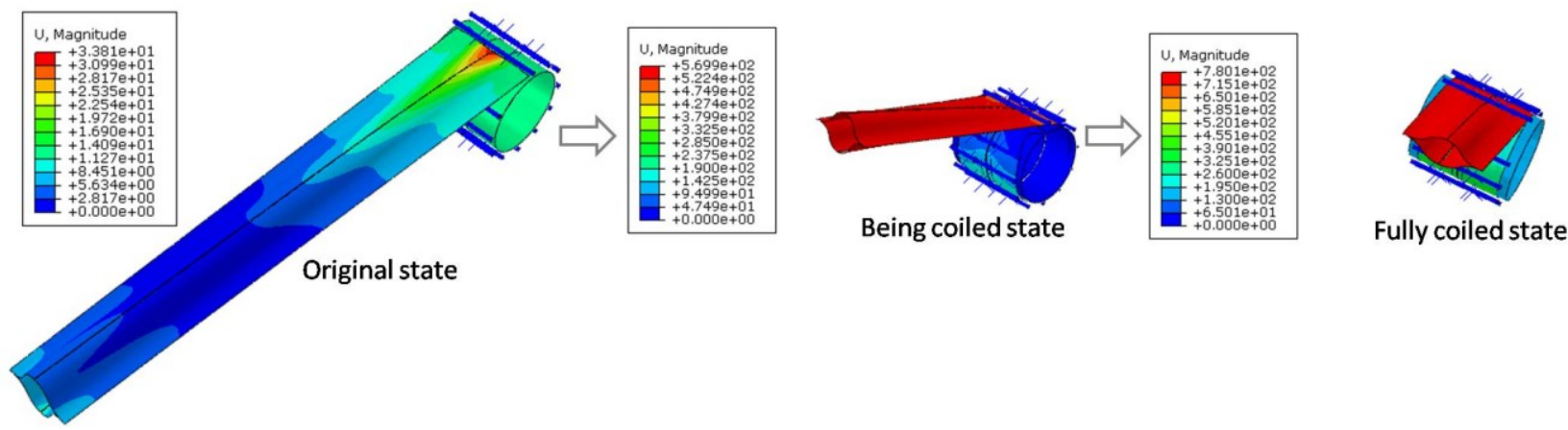

(b) Simulations

Figure 8 Folding deformation of the DCB

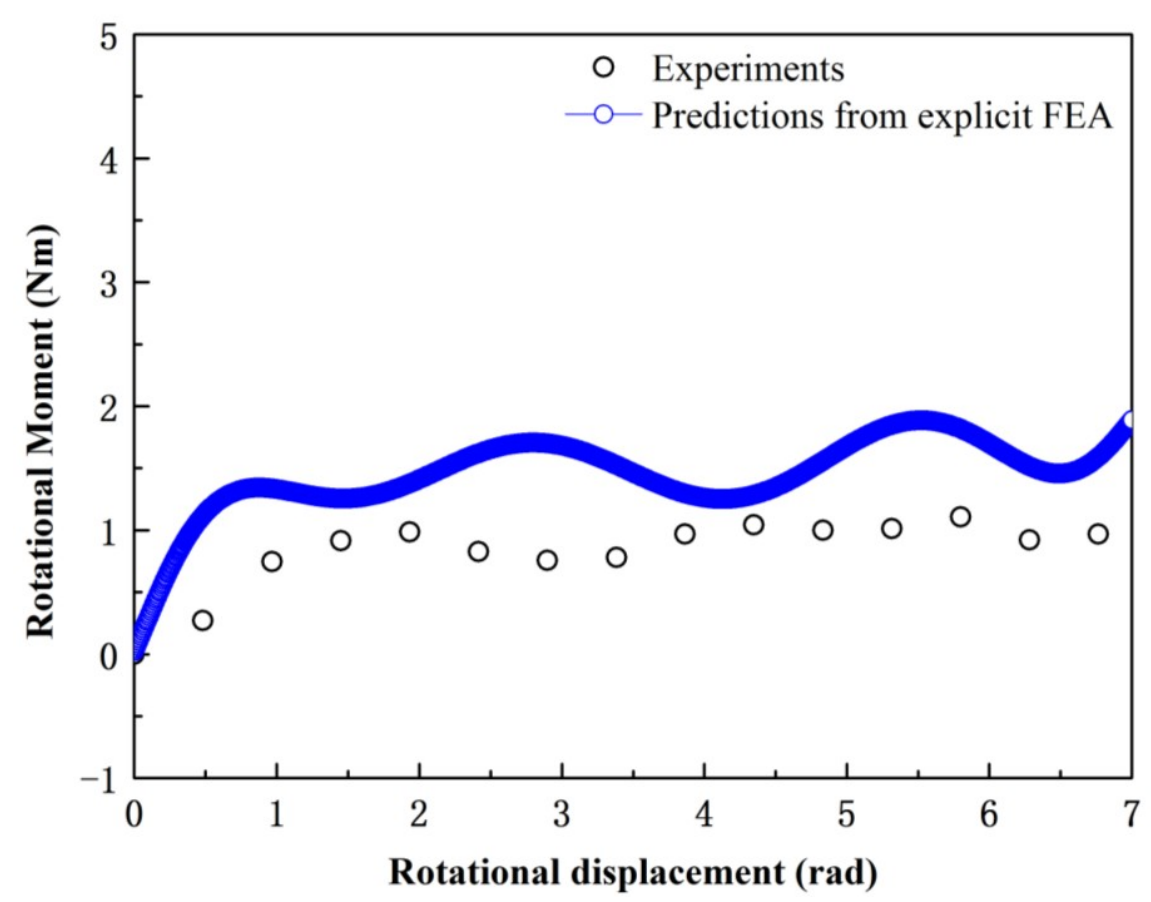

Figure 9 Rotational moment versus rotational displacement curve of the DCB in folding deformation

\section{FOLDING ANALYSIS}

In reality, in the folding deformation of the $\mathrm{DCB}$, significant geometric changes and complex 
contacts between different parts of folding system always cause the singularities of the stiffness matrix to result in the difficulty of solving convergence in dynamic analysis ${ }^{[21]}$. Fortunately, the problem can be solved by means of the ABAQUS explicit solver. For this reason, the geometrically nonlinear explicit dynamic analysis based on ABAQUS code are implemented for numerical simulations of folding deformation.

\subsection{Tensile and Compression Deformations}

For an DCB in tensile as shown in Figure 10, an analytical model is valid to predict the load-displacement curves ${ }^{[17,18]}$. Namely, the deflections at the point $\mathrm{C}$ in a horizontal direction in tensile deformation and at the apex $\mathrm{A}$ in vertical direction in compression deformation are respectively

$$
\begin{gathered}
\delta_{y}=2 r \sin \varphi-2 r_{0} \sin \varphi_{0} \\
\delta_{z}=2 r(1-\cos \varphi)-2 r_{0}\left(1-\cos \varphi_{0}\right)
\end{gathered}
$$

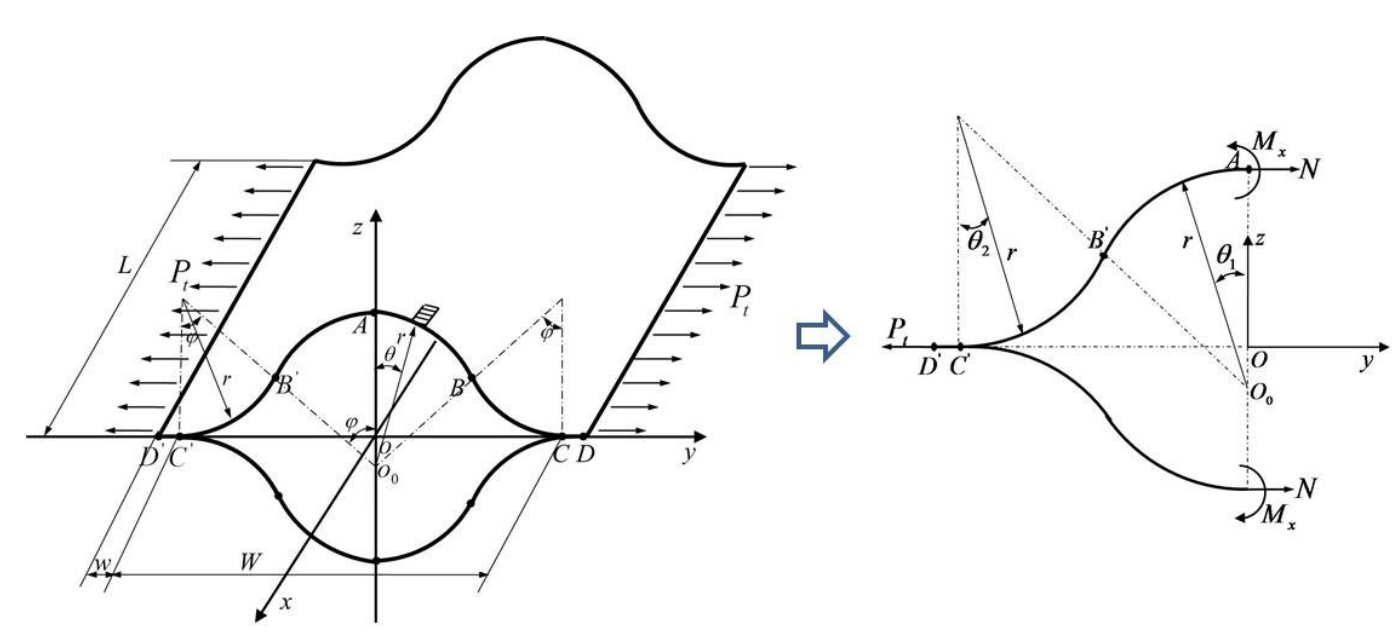

Figure 10 Geometrical configurations and restraint forces of the DCB in tensile

The tensile force of the DCB in tensile deformation and the flattening force of the DCB in compression deformation are respectively expressed as

$$
\begin{aligned}
& P_{t}=\frac{2 M_{x}}{r(1-\cos \varphi)} \\
& P_{C}=\frac{2 M_{x}}{r \sin \varphi}
\end{aligned}
$$

where $M_{x}$ is the resultant moment in the direction of $x$ axis and is determined as 


$$
M_{x}=C_{0} \int_{-\frac{t_{0}}{2}}^{\frac{t_{0}}{2}}\left(E_{\theta} \frac{\Delta r}{r_{0}+\Delta r}\right) d \Delta r
$$

Using the Equations (1) to (5), the load-displacement curves of the DCB subjected to tensile and compressive loadings can be respectively plotted (shown in Figures 5 and 7). From Figures 5 and 7, it is clear that the load-displacement curves predicted from analytical model agree well with the experiments.

According to the geometry and dimensions of the DCB (shown in Figure 1), 3D FE models for the DCB under tensile and compressive loadings are generated by using ABAQUS code (shown in Figure 11). In order to save computational time, a length of $10 \mathrm{~mm}$ for the DCB, rather than the length of $65 \mathrm{~mm}$ for the specimen, is chosen for the explicit analysis on tensile and compressive behaviours, by considering the structural symmetries, loadings and boundary conditions. In both FE models, the layered shell element S4R is utilised to model the DCB and the total number of elements is 480 . The same type of element as the DCB is employed to model the rigid plates in the FE model subjected to compressive loading and the total number of elements is 144 for each of them (shown in Figure 11b). The contact type between the DCB and rigid plates is defined as the general contact. The mechanical properties of the materials in FE models are listed in Table 1.

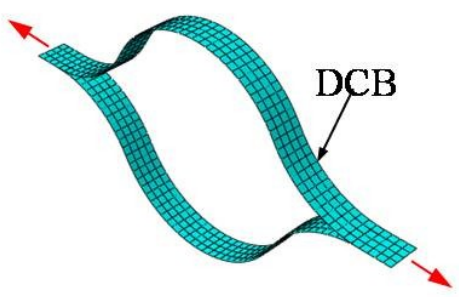

(a) Tenisle

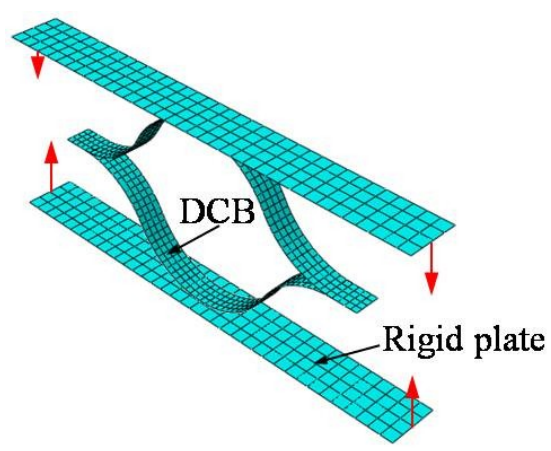

(b) Compression

Figure 11 FE models of the DCB under tensile and compression loadings

Table 1 Mechanical properties of T300/5228A

Longitudinal Young's modulus $E_{1} / \mathrm{GPa} \quad 80.08$

Transverse Young's modulus $E_{2} / \mathrm{GPa} \quad 6.67$

Poisson's ratio $v_{12}$

In-plane shear modulus $G_{12} / \mathrm{GPa}$ 


$$
\begin{array}{cc}
\text { Inter-laminar shear modulus } G_{13} / \mathrm{GPa} & 2.93 \\
\text { Inter-laminar shear modulus } G_{23} / \mathrm{GPa} & 2.50 \\
\text { tensile strength } X_{t} / \mathrm{MPa} & 1063.48 \\
\text { compressive strength } X_{\mathrm{c}} / \mathrm{MPa} & 662.69 \\
\text { shear strength } S / \mathrm{MPa} & 126.76 \\
\text { Destiny } \rho / \mathrm{kg} \cdot \mathrm{m}^{-3} & 1.6 \times 10^{3} \\
\text { Ply thickness } / \mathrm{mm} & 0.08
\end{array}
$$

Owe to the excessive distorted mesh elements or high deformation rate, there often exists the numerical instability in large deformation simulation. In order to perform stable explicit analysis, the step time (i.e., total time) for whole deformation process is always divided into many shorter time increments or intervals, and the time increment $\Delta t$ cannot be longer than the maximum stable time increment $\Delta t_{\max }$, which can be expressed as ${ }^{[21]}$

$$
\Delta t=\alpha \cdot \Delta t_{\max }=\alpha \cdot\left(\sqrt{1+\xi^{2}}-\xi\right) \frac{l_{\min }}{c_{d}}
$$

where $\alpha$ is the time scaling factor within the range from 0 to $1 ; \xi$ is the fraction of critical damping in the highest frequency mode; $l_{\min }$ is the shortest element edge length; $c_{d}$ is the dilatational wave speed. Using the same method as in literature [21], the time scaling factor $\alpha$ is defined to be 1.0 , and the element size, mass scaling and damping are adjusted to satisfy the requirements of stable explicit analysis. In addition, the default of critical damping in ABAQUS code is used, and the maximum stable time increment is about $4.505 \times 10^{-7}$ seconds. The standard FEA and geometrically nonlinear explicit FEA at six given step times of $1 \mathrm{~s}, 0.5 \mathrm{~s}, 0.1 \mathrm{~s}, 0.05 \mathrm{~s}, 0.02 \mathrm{~s}$ and $0.01 \mathrm{~s}$ are undertaken, and the simulated results are shown in Figures 4 to 7, 12 to 15 .

From Figures 4 to 7, 12 to 15 , it is distinct that, (i) the DCB gradually stretches until completely flattening with an increase in the loading of tensile or compression (see Figures 4 and 6), and the load-displacement curves predicted from standard FEA and geometrically nonlinear explicit FEA at a given step time of longer than 0.02s correlate well with the experiments (see Figures 5 and 7). We therefore conclude that both standard FEA and geometrically nonlinear explicit FEA at a given long step time can appropriately and effectively simulate the quasi-static tensile and compressive 
deformations of the DCB; (ii) the strain energies in the DCB predicted from standard FEA are almost coincide with those from geometrically nonlinear explicit FEA (see Figure 12), whereas the kinetic energies predicted from geometrically nonlinear explicit FEA are much larger for step times of $0.01 \mathrm{~s}$ and $0.02 \mathrm{~s}$ than for other step times (see Figure 13). This is because in geometrically nonlinear explicit FEA, too small step time can contribute to a significant kinetic effect, appreciable deviating from quasi-static tensile or compression deformation in tests; (iii) all load-displacement curves look like nonlinear (see Figures 5 and 7). The nonlinear load-displacement curves can be attributed to the fact that bending stress plays a dominant role within approximately linear range, whereas there are both bending and membrane stresses within nonlinear range; (iv) the principal normal stress $\sigma_{1}$ and shear stress $\tau_{12}$ along the cross-sectional path of flattened DCB are quite small (see Figure 14). This demonstrates that the DCB can stretches and recovers elastically; and (v) in geometrically nonlinear explicit FEA, the CPU time increases with an increase in the step time (see Figure 15).

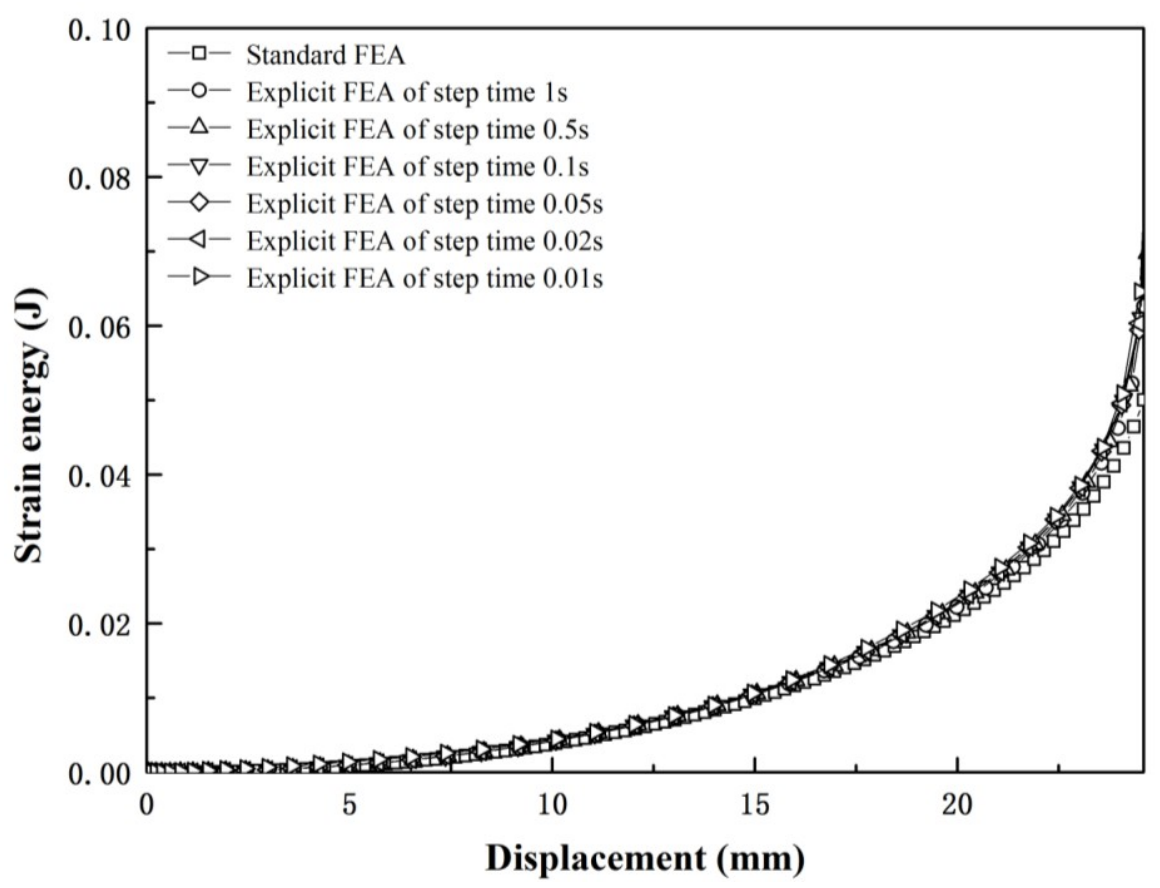

(a) tensile 


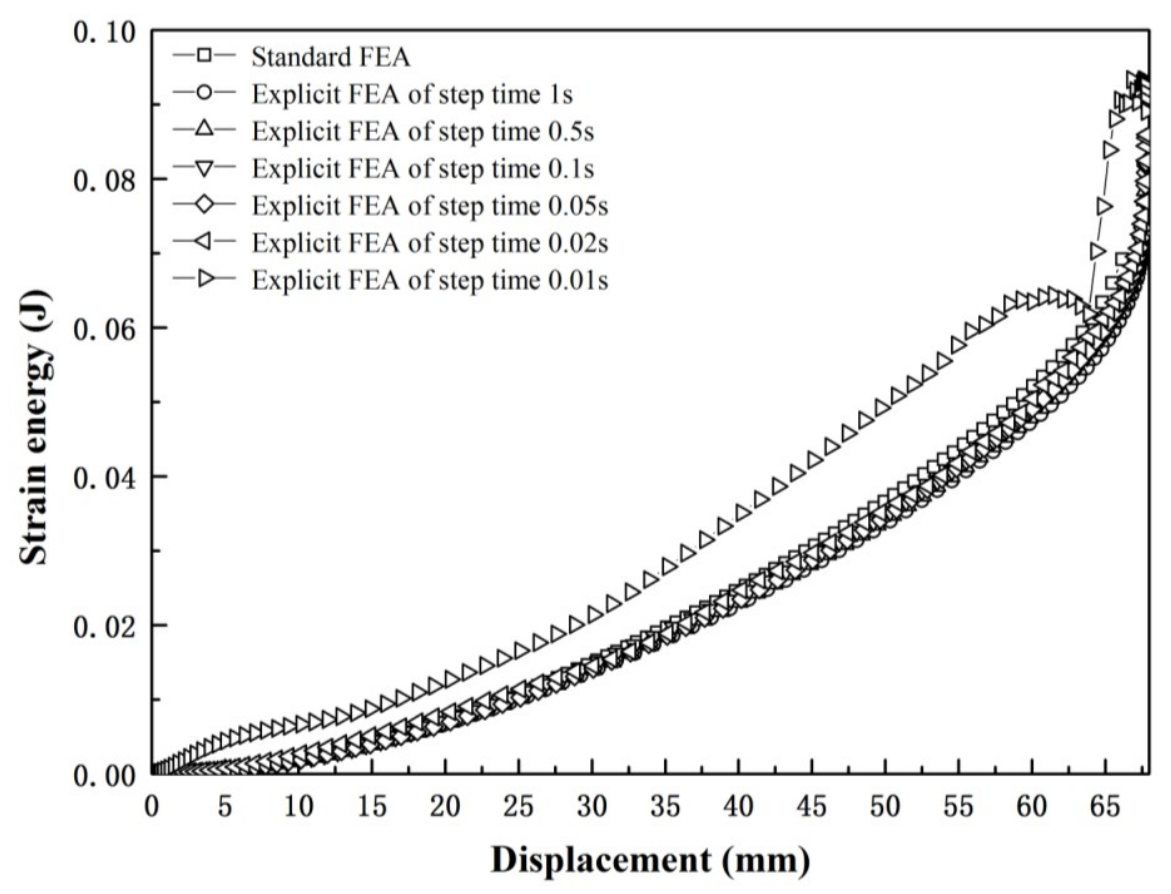

(b) compression

Figure 12 Strain energy versus displacement curves of the DCB

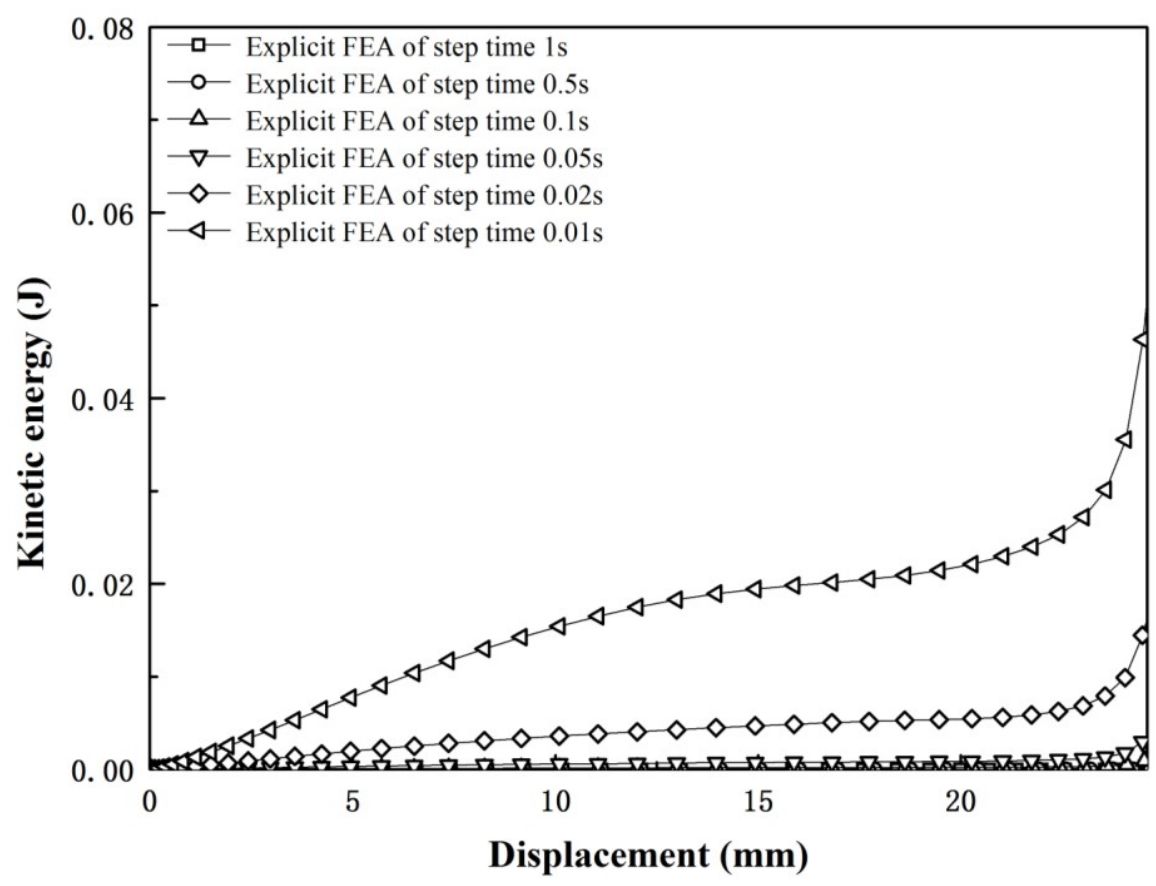

(a) tensile 


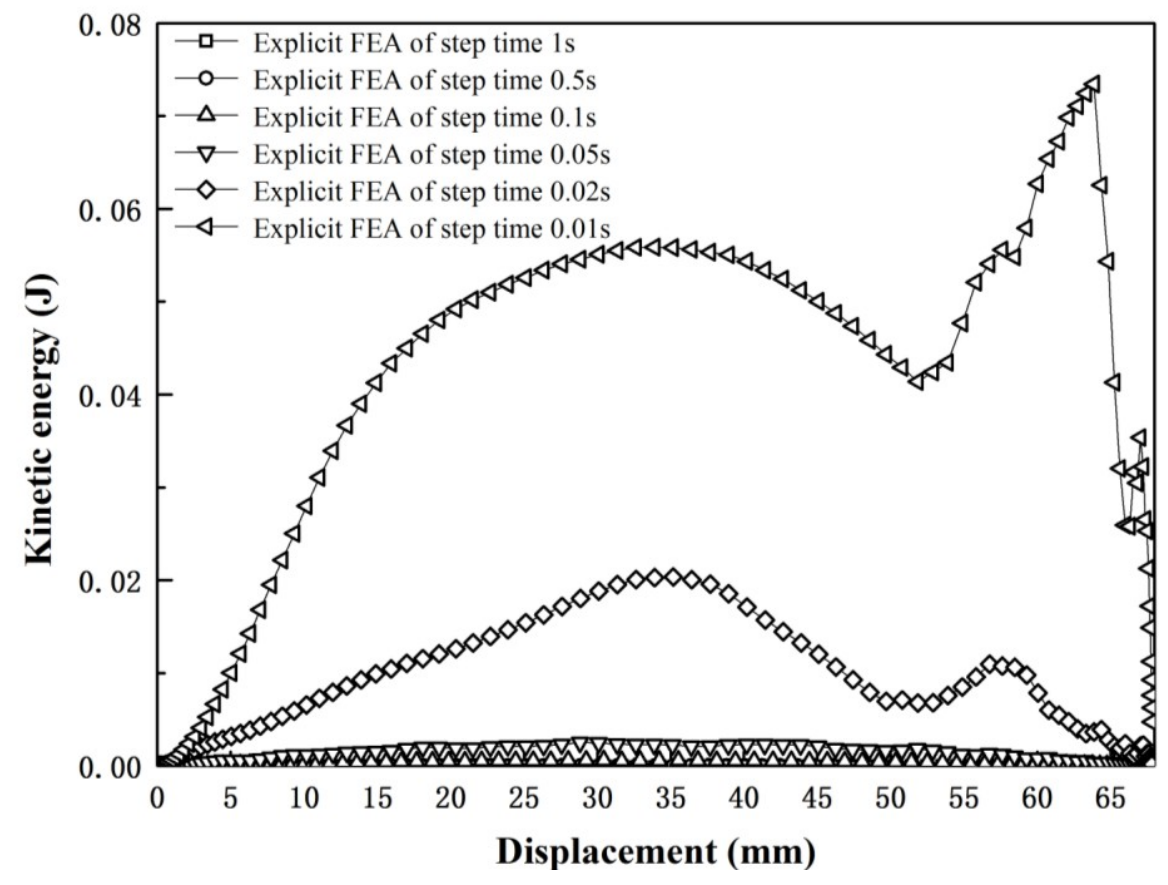

(b) compression

Figure 13 Kinetic energy versus displacement curves of the DCB

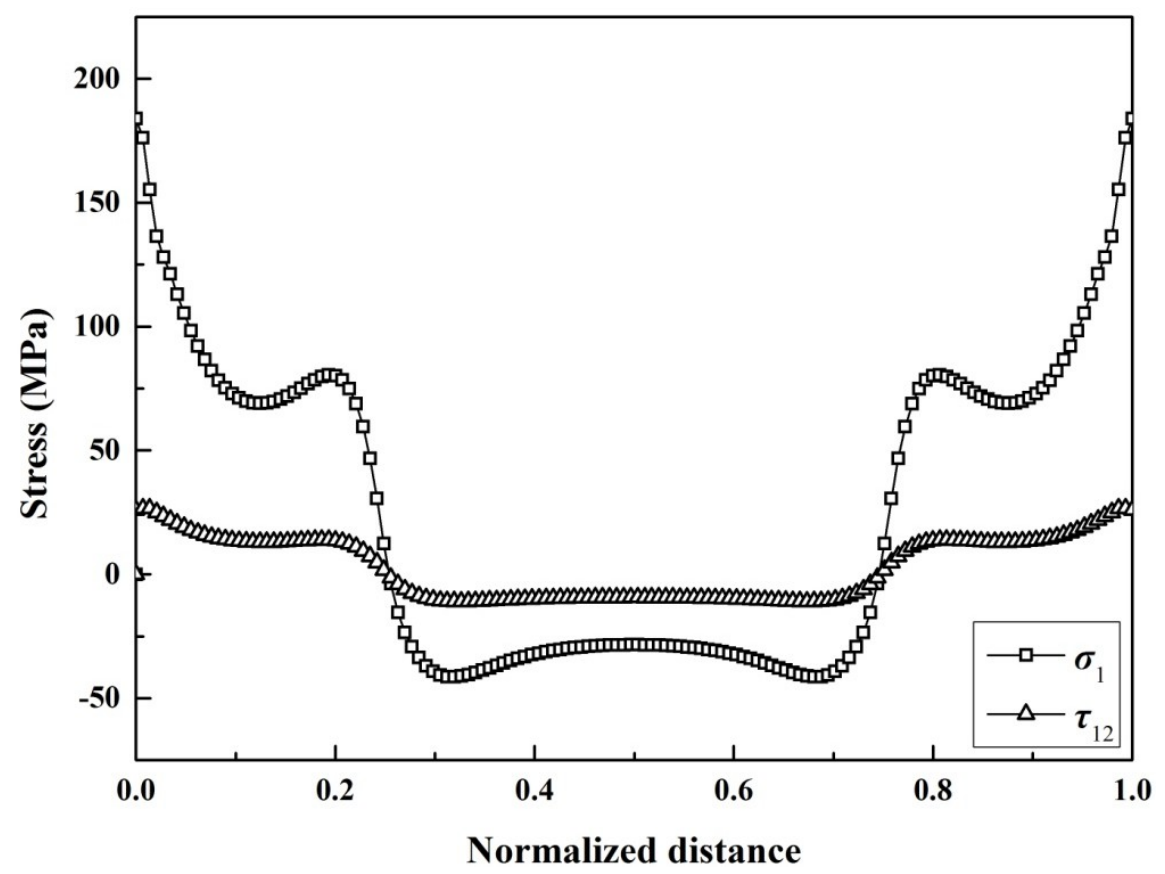

(a) tensile 


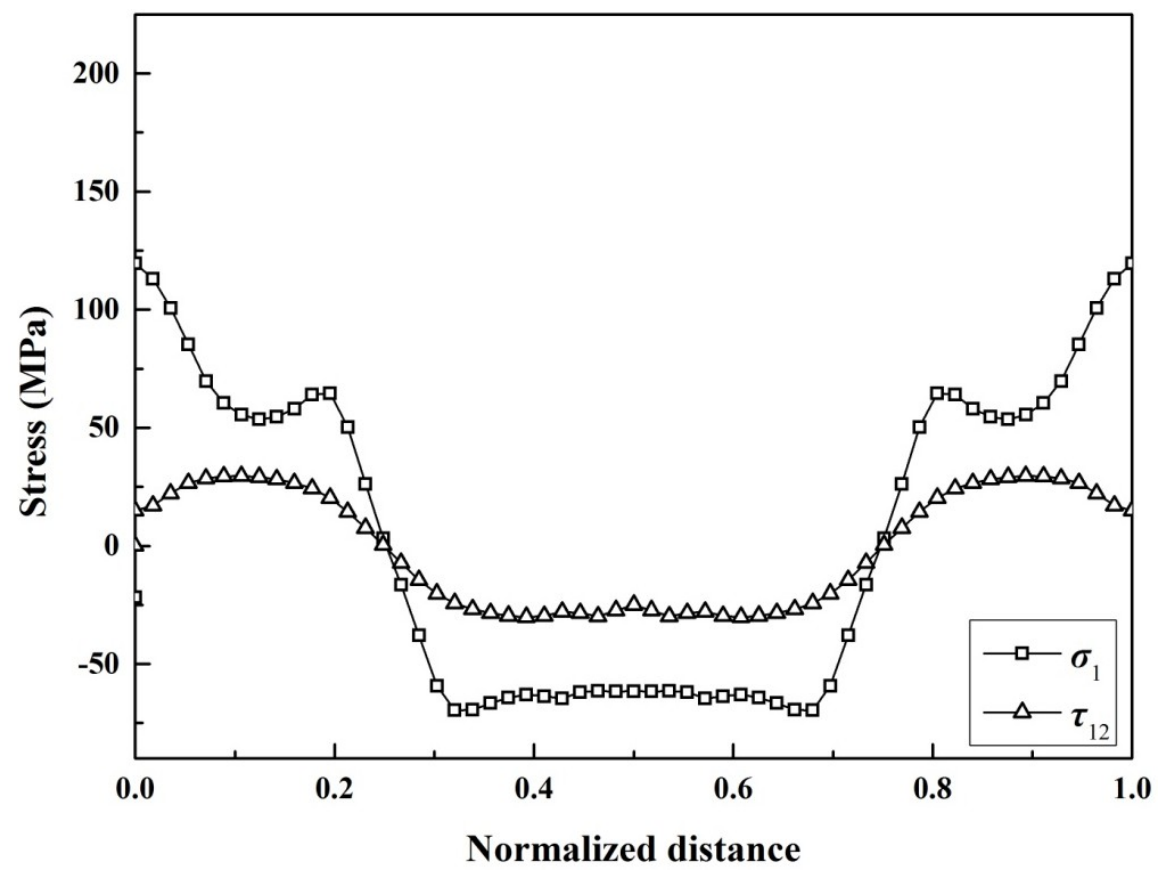

(b) compression

Figure 14 Surface stress pattern along cross-sectional path of flattened DCB

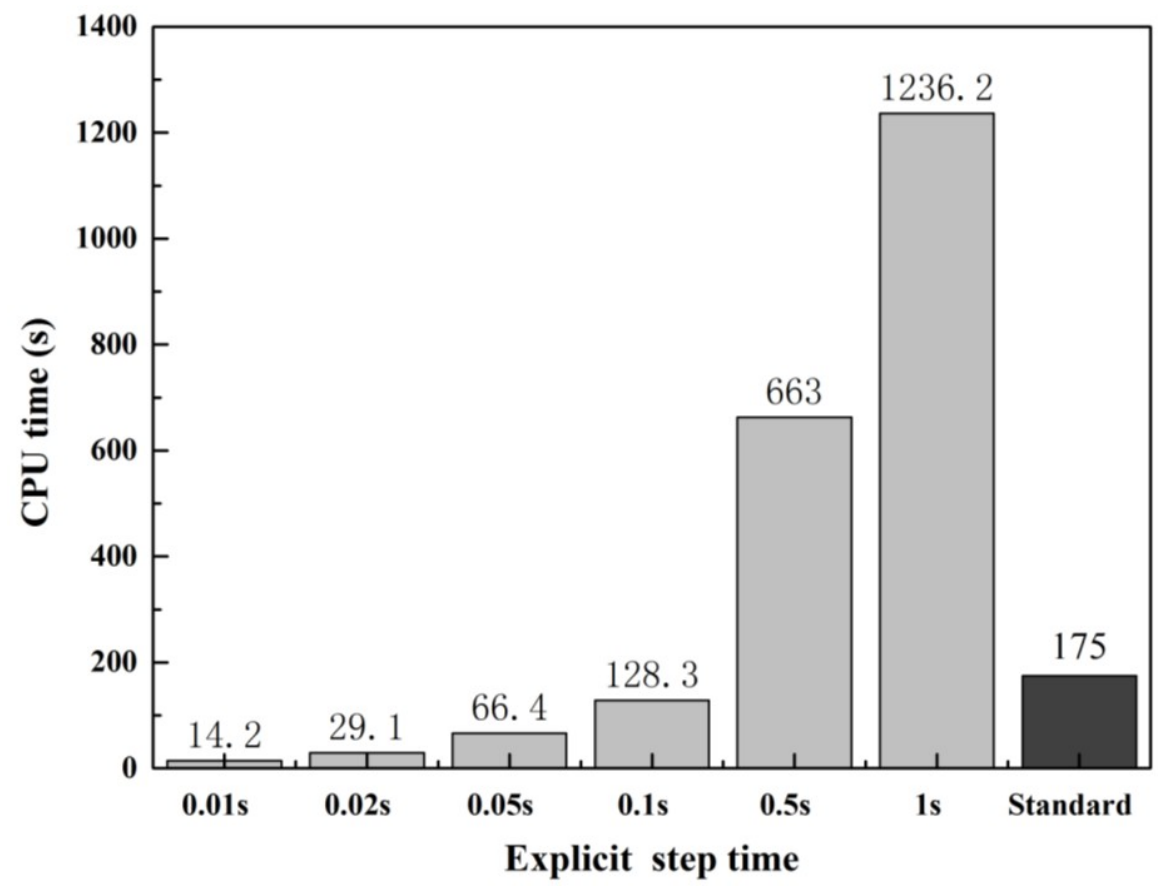

(a) tensile 


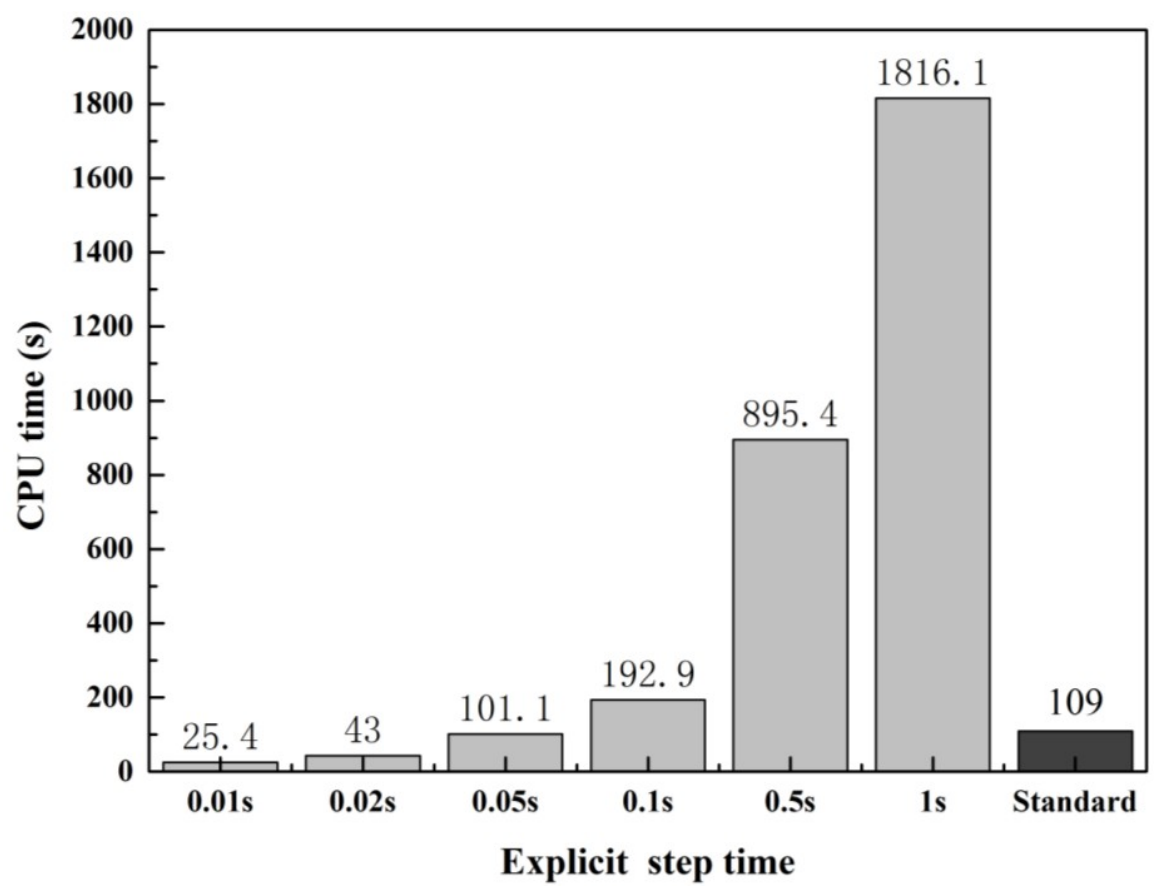

(b) compression

Figure 15 CPU time versus explicit step time for FEA

\subsection{Folding Deformation}

Due to the complexity for modelling the contacts between the DCB and the central driving roller, and between the DCB and the constraint shafts in a folding deformation, the standard FEA is not appropriate and valid for folding deformation analysis, but the geometrically nonlinear explicit FEA is still available to deal with the contact modelling. For this reason, by resorting to geometry and dimensions of the DCB and experimental device (shown in Figure 8), a 3D geometrically nonlinear explicit FE model of the DCB is generated by using ABAQUS code (shown in Figure 16). Because of the symmetry features of the DCB, a half-model of the DCB with symmetrical boundary conditions is adopted to reduce the computational time. Similarly, the layered shell element S4R is also employed to model the DCB, central driving roller and constraint shafts, and the total numbers of elements are 9750, 2200 and 550 respectively, as well as the mechanical properties of material are listed in Table 1. The contacts between the DCB and the central driving roller, and between the DCB and the constraint shafts are defined as the general ones in the geometrically nonlinear explicit FE model, and the kinematic coupling constraint between the central driving roller and the DCB is defined as the hinged support constraint to make the DCB stretching and coiling along the central driving roller. The folding deformation of the DCB in the FE model is decomposed into two steps: (i) a tensile deformation at one end of the DCB until completely flattening; and (ii) a coiling 
deformation of completely flattening DCB. Based on the aforementioned analysis on step time, the step times for both steps are chosen to be $1 \mathrm{~s}$ and $2 \mathrm{~s}$, respectively. The simulations for folding deformation process are shown in Figures 8 and 9, 17 to 19.

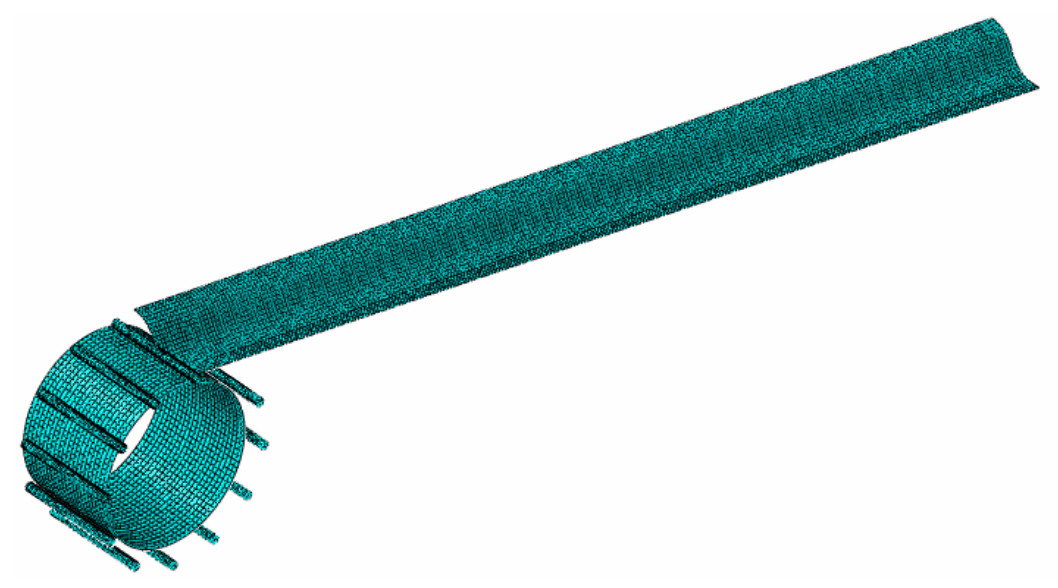

Figure 16 FE model for folding deformation of the DCB

From Figures 8 and 9, 17 to 19, it is evident that, (i) the DCB is stably coiled along the central driving roller (see Figure 8), which is correlated well with the experiments. Moreover, the predictions for rotational moment versus rotational displacement curves of the DCB agree well with the experimental results (see Figure 9); (ii) the strain energy in the DCB increases with an increase in the tensile and rotational displacements. In comparison with the strain energy, the kinetic energies predicted from the FEA are so small to be neglected (see Figure 17); (iii) during the tensile deformation of the DCB, the maximum compressive and tensile stresses respectively occur at the central convex arc and at the side concave arc on the end-section (see Figure 18a); (iv) during the coiling deformation, the maximum compressive and tensile stresses separately appear on the internal surface and external surface (see Figure 18b); (v) as compared with compressive and tensile stresses, the shear stress in whole folding deformation is negligible small (see Figure 19). Meanwhile, the maximum stresses of the DCB in whole folding deformation are much less than ultimate strengths of material (see Figure 18). Thus, the DCB can fold and deploy elastically.

Significant results that emerged from the above comparisons and analysis are summarized as follows: (i) it is evitable for the explicit method to induce a certain calculation error due to the kinetic effect at a given short step time. However, geometrically nonlinear explicit FEA method seems more efficient than implicit method to deal with the solution instability in quasi-static large folding deformation analysis. (ii) the methods and models arising from the geometrically nonlinear explicit FEA for large tensile or compressive deformation are helpful, rather than directly available 
for large folding deformation analysis. This is because there are significant differences in the geometry and kinetic effect between large tensile (or compressive) and folding deformations.

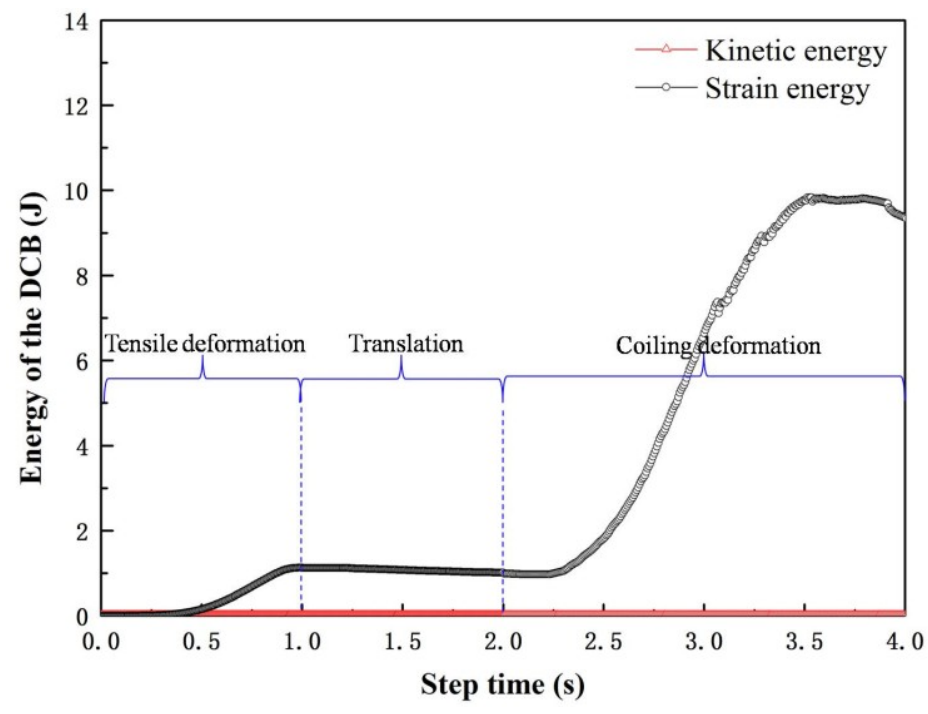

Figure 17 Strain energies of the DCB in the folding deformation

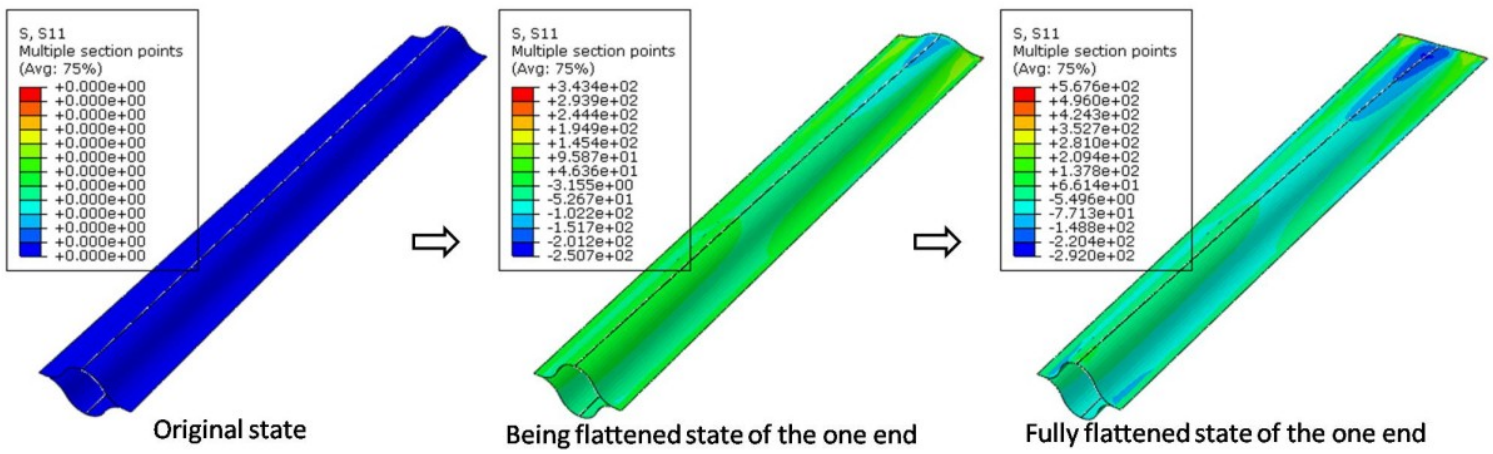

(a) Tensile deformation at the end of the DCB

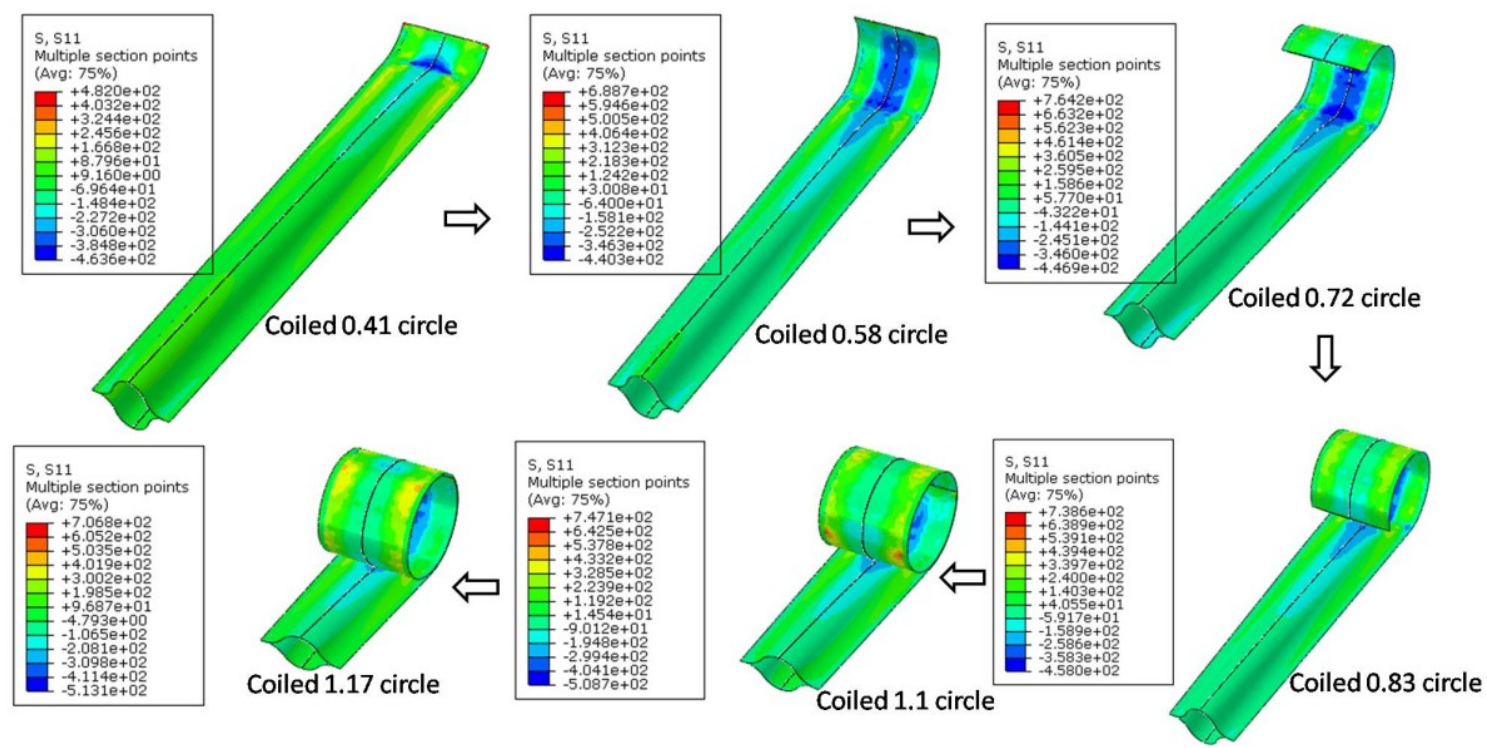

(b) Coiling deformation

Figure 18 Surface stress patterns of the DCB in the folding deformation 


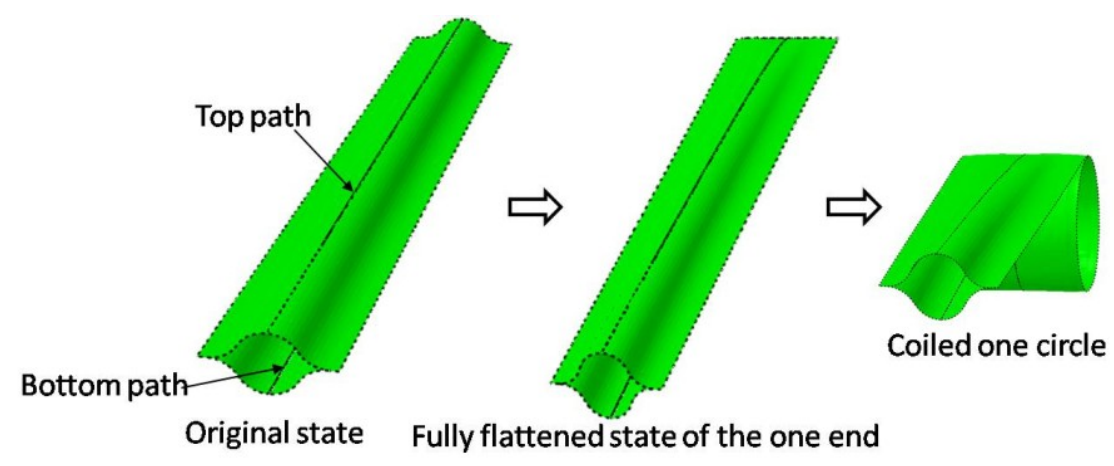

(a) Top and bottom paths for stress analysis

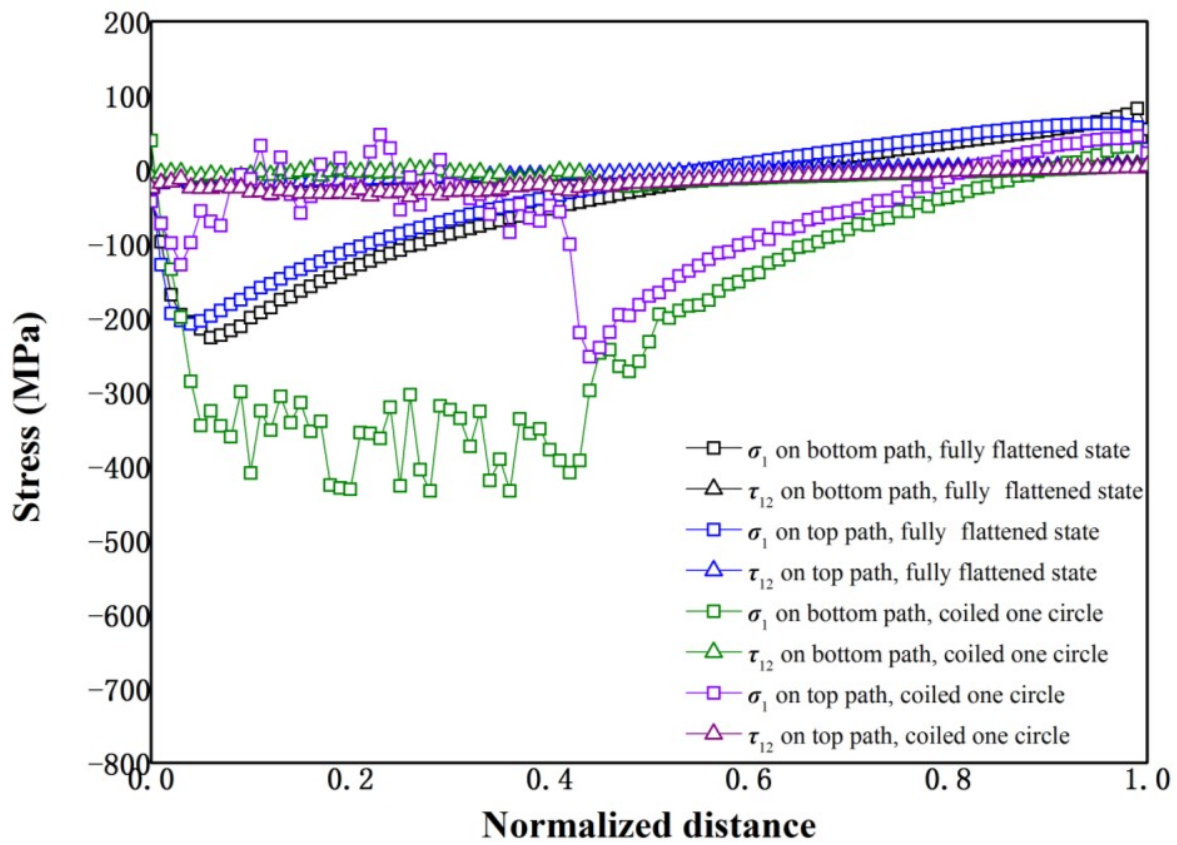

(b) Stress distributions

Figure 19 Surface stress curves along top and bottom paths of the DCB in folding deformation

\section{CONCLUSIONS}

The large deformation behaviour of thin-walled deployable composite boom made of carbon-fibre-reinforced-plastics with high strain ability is investigated through experimental, numerical and theoretical methods. Particular novel features are three-fold:

(1) Large deformation function tests were conducted on the DCB under tensile, compression and folding deformation loadings, and it is found that the DCB can deforms and recovers elastically, and the load-displacement curves of the DCB in tension and compression deformations exist nonlinear characteristic.

(2) Although there is a significant kinetic effect in geometrically nonlinear explicit FEA at a given short step time for large deformation analysis of the $\mathrm{DCB}$, geometrically nonlinear explicit FEA method seems more efficient than implicit method to deal with the solution instability in 
quasi-static large folding deformation analysis. A good correlation between predictions and experiments has been achieved.

(3) From the stress patterns simulated from geometrically nonlinear explicit FEA, it is clear that the maximum stresses of the DCB in large folding deformation are much less than ultimate strengths of material. This result implies that the DCB can deforms and recovers elastically.

\section{ACKNOWLEDGEMENTS}

This project was supported by the National Natural Science Foundation of China (Grant No. 51875026 and 51875021). The authors are grateful to reviewers and editors for helpful suggestions.

\section{REFERENCES}

[1] Wu R, Roberts PCE, Soutis C, Diver C. Flexible heat shields deployed by centrifugal force. Acta Astronautica, doi.org/10.1016/j.actaastro.2018.06.021.

[2] Xiong JJ, Shenoi RA. General aspects on structural integrity. Chinese Journal of Aeronautics, http://doi.org/10.1016/j.cja.2018.07.18.

[3] Huang H, Guan FL, Pan LL, Xu Y. Design and deploying study of a new petal-type deployable solid surface antenna. Acta Astronautica, 2018; 148: 99-110.

[4] Cai J, Ren Z, Ding YF, Deng XW, Xu YX, Feng J. Deployment simulation of foldable origami membrane structures. Aerospace Science and Technology, 2017; 67: 343-353.

[5] Chu Z, Deng Z, Qi X, Li B. Modeling and analysis of a large deployable antenna structure. Acta Astronautica, 2014; 95: 51-60.

[6] Puig L, Barton A, Rando N. A review on large deployable structures for astrophysics missions. Acta Astronautica, 2010; 67:12-26.

[7] Leipold M, Fichtner H, Heber B, Groepper P, Lascar S, Burger F, Eiden M, Niederstadt T, Sickinger C, Herbeck L, Dachwald B, Seboldt W. Heliopause Explorer: a sailcraft mission to the outer boundaries of the solar system. Acta Astronautica, 2006; 59: 785-796.

[8] Block J, Straubel M, Wiedemann M. Ultra-light deployable booms for solar sails and other large gossamer structures in space. Acta Astronautica, 2011; 68: 984 - 992.

[9] Mallikarachchi HMYC, Pellegrino S. Quasi-static folding and deployment of ultra thin composite tape-spring hinges. Journal of Spacecraft and Rockets, 2011; 48(1): 188-197. 
[10] Soykasap Ö. Analysis of tape spring hinges. International Journal of Mechanical Sciences, 2007; 49: 853-860.

[11] Soykasap Ö. Folding design of composite structures. Composite Structures, 2007; 79: 280-287.

[12] Seffen KA, You Z, Pellegrino S. Folding and deployment of curved tape springs. International Journal of Mechanical Sciences, 2000; 42: 2055-2073.

[13]Dewalque F, Schwartz C, Denoël V, Croisier JL, Forthomme B, Brüls O. Experimental and numerical investigation of the nonlinear dynamics of compliant mechanisms for deployable structures. Mechanical Systems and Signal Processing, 2018; 101: 1-25.

[14]Dewalque F, Rochus P, Brüls O. Importance of structural damping in the dynamic analysis of compliant deployable structures. Acta Astronautica, 2015; 111: 323-333.

[15] Sickinger C, Herbeck L, Breitbach E. Structural engineering on deployable CFRP booms for a solar propelled sailcraft. Acta Astronautica, 2006; 58: 185-196.

[16] Soykasap Ö. Deployment analysis of a self-deployable composite boom. Composite Structures, 2009; 89: 374-381.

[17]Bai JB, Xiong JJ, Gao JP, Yi XS. Analytical solutions for predicting in-plane strain and interlaminar shear stress of ultra-thin-walled lenticular collapsible composite tube in fold deformation. Composite Structures, 2013; 97: 64-75.

[18]Bai JB, Chen D, Xiong JJ, Shenoi RA. A corrugated flexible composite skin for morphing applications. Composites Part B: Engineering, 2017; 131: 134-143.

[19]JB Bai, JJ Xiong. Temperature effect on buckling properties of ultra-thin-walled lenticular collapsible composite tube subjected to axial compression. Chinese Journal of Aeronautics, $2014 ; 27(5): 1312-1317$.

[20]Bai JB, Shenoi RA, Xiong JJ. Thermal analysis of thin-walled deployable composite boom in simulated space environment. Composite Structures, 2017; 173: 210-218.

[21] Stabile A, Laurenzi S. Coiling dynamic analysis of thin-walled composite deployable boom. Composite Structures, 2014;113: 429-436.

[22]Barbera D, Laurenzi S. Nonlinear buckling and folding analysis of a storable tubular ultrathin boom for nanosatellites. Composite Structures, 2015 ;132: 226-238.

[23]Fernandez JM. Advanced deployable shell-based composite booms for small satellite applications including solar sails, 4th International Symposium on Solar Sailing. Kyoto, Japan, 17-20 January 2017. 
[24]Fernandez JM, Visagie L, Schenk M, Stohlman OR, Aglietti GS, Lappas VJ, Erb S. Design and development of a gossamer sail system for deorbiting in low earth orbit. Acta Astronautica, 2014; 103: 204-225. 